\title{
Mechanical properties of fly ash and blast furnace slag based alkali activated concrete using high silica modulus activator
}

\author{
Dr.G.V.V.Satyanarayana ${ }^{1}$, Kaparaboina Greeshma $^{2}$ \\ ${ }^{1}$ Professor of Civil Engineering Department, GRIET, Hyderabad. \\ ${ }^{2} \mathrm{M}$. Tech student Department of Civil Engineering, GRIET, Hyderabad
}

\begin{abstract}
The alternative to cement is grabbing attention of inventors due to the numerous advantages with their usage. Fly Ash (FA) and Blast furnace slag (BFS) are abundantly available in bi product form. There is heavy problem in disposal and land availability for industries. So many studies are going on to reduce these problems by usage as cementitious materials in concrete adding advantages towards green concrete. It is developed that Alkali activated flyash concrete has high strength, high acid resistance and heat resistance where as Alkali activated slag concrete has rapid setting time, high strength, impermeable and improved fire resistance. In this study FA and BFS are activated with high silica modulus activator with different activator/binder ratios and binder contents. The alkali activated FA-BFS concrete is verified for workability, compressive strength, split tensile strength, and flexural strength.
\end{abstract}

Keywords Fly Ash (FA) and Blast furnace slag (BFS) based alkali activated concrete (AAC), High silica modulus, Activator/binder ratio, Mechanical properties, ambient curing.

\section{Introduction}

Cement is the primarily used constituent material for binding material in conventional concretes so its usage and demand is higher since so many decades. Manufacture of cement contributes to negative impact on environment mainly depletion of ozone layer and different raw materials like lime stone and sand. On this aspect the researchers are finding solution to protect natural resources. Alkali activated concrete is one of the response towards this environmental concern. Alkali activated binders such as inorganic polymers alkalibonded ceremics, geopolymers are environmental friendly materials. Alkali activated binder reduced the effect of deplication of raw materials along with advantages of high compressive strength, fire resistance, rapid setting time, low shrinkage, resistance of alkali aggregate reaction, freeze-thraw resistance and markable durability. Generally Fly Ash (FA) and Blast furnace slag are mostly used binders.

Shah, Syed Farasat Ali, et al [1] studied on the impact of slag content, activator, retarder content and curing effects on the fresh and hardened properties of AAFSC. Compressive strength and flexure strength results indicated that curing condition governed that strength of alkali activated mortars. SEM conformed improved geo polymerization reaction at heat curing leads to increase in early strength. Dr.G. V. V Satyanarayana, and C. Saikiran [2] stated that increase in compressive strength was observed upto $50 \%$ of fine aggregate replacement with copper slag. The split tensile strength and flexural strength decreased due to less interlocking space between concrete ingredients. Zhou, Xianyu, et al [3] studied that AAM'S are alternatives for Portland cement but the problem of shrinkage and cracking of these binders is deduced by adding basalt and PP reinforced fiber in concrete in this investigation. With increase in basalt fibre dosage and its length compressive strength increased initially later it decreased where as split tensile strength, flexural strength increased with increasing fiber dosage later there was decrease in split tensile strength. Kishore and Kamal, et al [4] concluded when GGBS is partially replaced by metakaolin with $\mathrm{NaOH}$ and $\mathrm{Na}_{2} \mathrm{SiO}_{3}$ the setting time increased whereas compressive strength decreased. Fang and Guohao, et al [5] studied the mechanism of microstructural evolution of interfacial transition zone in AAFSC using SEM. For one day quick reaction of activator/binder leads to increase in formation of reaction products, for seven days the dissolved species increases along with high $\mathrm{Ca} C-(\mathrm{N})-\mathrm{A}-\mathrm{S}-\mathrm{H}$ and C-A-S-H. For 28 days compact dense $\mathrm{Ca}$ C-(N)-A-S-H 
microstructure with rich $\mathrm{Si}, \mathrm{Al}$ is formed. Bhardwaj and Bavita, et al [6] concluded that by replacing foundry sand in GPC and AASC workability decreased. In GPC $100 \%$ replacement gave maximum strength of $43 \%$ of 28 days, where as AASC on replacing 40-60\% with foundry sand achieved more than $77 \%$ compared to GPC. Tensile strength is same as compressive strength. Marjanovic and Natasa, et al [7] studied AAFSC for varing proportions of Fly Ash, blast furnaces slag and activator concentration. And stated that compressive strength depends on composition of blend of flyash, blast furnaces slag and the water/binder ratio whereas the setting time depends on activator concentration. Fly Ash alkali reaction in binding face influence flexural strength where as blast furnaces slag alkali reaction influence the compressive strength. Chi, Maochieh, and Ran Huang [8] studied AAFSC was produced with silica modulus 1 where $\mathrm{Na}_{2} \mathrm{O}$ concentration of $4 \%$ and $6 \%$ with liquid/binder the results showed that Flyash/slag ratio and dosage ratio are influencing factor of binding mechanism and properties of AAFSC. The compressive strength and flexural strength are higher compared to OPCC. FA need curing at elevated temperatures whereas BFS has rapid setting time to eradicate these problems combination of FA and BFS with high silica modulus of 2.91 is used as activator. In this article three different activator/binder ratio with FABFS binder content of $500 \mathrm{Kg} / \mathrm{m}^{3}$ are prepared to conducted compressive strength, split tensile strength, and flexural strength.

\section{Materials}

The combination of FA and BFS are used as binders. The specific gravity of FA and BFS are 2.6 and 2.8 respectively. The mineralogical composition of FA and BFS are in Table 1. The fine aggregate is the river sand with maximum size of $2.5 \mathrm{~mm}$. The coarse aggregate is of maximum size $20 \mathrm{~mm}$. High silica modulus sodium silicate solution is used as activator. This neutral activator with $\mathrm{SiO}_{2}: \mathrm{Na}_{2} \mathrm{O}$ ratio 2.91 used without any admixtures.

Table 1: Mineralogical composition of FA and BFS

\begin{tabular}{|l|l|l|}
\hline Chemicals & FA (wt\%) & BFS (wt\%) \\
\hline $\mathrm{CaO}$ & 6.9 & 42.3 \\
\hline $\mathrm{Na}_{2} \mathrm{O}$ & 0.63 & 0.34 \\
\hline $\mathrm{SiO}_{2}$ & 50.2 & 35.9 \\
\hline $\mathrm{Al}_{2} \mathrm{O}_{3}$ & 23.2 & 12.8 \\
\hline $\mathrm{MgO}$ & 1.2 & 6.03 \\
\hline $\mathrm{Fe}_{2} \mathrm{O}_{3}$ & 4.92 & 0.53 \\
\hline $\mathrm{K}_{2} \mathrm{O}$ & 1.32 & 0.321 \\
\hline $\mathrm{SO}_{3}$ & 1.49 & 1.79 \\
\hline $\mathrm{TiO}_{2}$ & 1.4 & 0.70 \\
\hline
\end{tabular}

\section{Concrete mixture}

In this study a total of six mixes were prepared and tested. The six mixes has constant binder content of $500 \mathrm{~kg} / \mathrm{m}^{3}$. The ratio of FA and BFS are 70:30 and 50:50. The activator/binder ratio of $0.6,0.65$ and 0.7 are considered. A total of 114 specimens are casted and tested. The details of concrete mix proportion are in table 2

Table 2: Mix proportions

\begin{tabular}{|c|c|c|c|c|c|c|}
\hline Mix & M1 & M2 & M3 & M4 & M5 & M6 \\
\hline $\begin{array}{l}\text { Binder } \\
\text { content } \\
\left(\mathrm{kg} / \mathrm{m}^{3}\right)\end{array}$ & 500 & 500 & 500 & 500 & 500 & 500 \\
\hline FA (\%) & 70 & 50 & 70 & 50 & 70 & 50 \\
\hline BFS (\%) & 30 & 50 & 30 & 50 & 30 & 50 \\
\hline $\begin{array}{l}\text { Activator/bi } \\
\text { nder }\end{array}$ & 0.6 & 0.6 & $\begin{array}{l}0.6 \\
5\end{array}$ & $\begin{array}{l}0.6 \\
5 \\
\end{array}$ & 0.7 & 0.7 \\
\hline $\begin{array}{l}\text { Fine } \\
\text { aggregate } \\
\left(\mathrm{kg} / \mathrm{m}^{3}\right)\end{array}$ & $\begin{array}{l}765 \\
.2\end{array}$ & $\begin{array}{l}765 \\
.2\end{array}$ & $\begin{array}{l}753 \\
.1\end{array}$ & $\begin{array}{l}753 \\
.1\end{array}$ & $\begin{array}{l}742 \\
.6\end{array}$ & $\begin{array}{l}742 \\
.6\end{array}$ \\
\hline $\begin{array}{l}\text { Coarse } \\
\text { aggregate } \\
\left(\mathrm{kg} / \mathrm{m}^{3}\right)\end{array}$ & 935 & 935 & 921 & 921 & 907 & 907 \\
\hline $\begin{array}{l}\text { Activator } \\
\left(\mathrm{kg} / \mathrm{m}^{3}\right)\end{array}$ & 300 & 300 & 325 & 325 & 350 & 350 \\
\hline
\end{tabular}

\section{Experimental procedure}

The normal consistency, initial setting time and final setting time tests are conducted for alkali activated FA BFS using vicat's apparatus similar to that of cement test. The test are done adding activator in place of water. The workability of FA-BFS based concrete for six mixes using slump cone test is conducted to ensure proper flowability of concrete. In this study to obtain mechanical properties of FA-BFS based AAC the trail based mix design proportions are shown in Table 2. The preparation of FABFS based AAC involved dry mixing of FA, BFS, fine aggregate and coarse aggregate. Then the activator is added and mixed for more 5-7 minutes till homogenous material is obtained. The specimens are casted, vibrated for 10 seconds and allowed to dry for 24 hours and then demoulded. The specimens are cured at ambient temperature and strengths are determined.

\section{Results and Discussions}

The normal consistency test of FA and BFS is comparable to cement. The normal consistency of FA and BFS achieved at $28 \%$ and $38 \%$ respectively. The initial setting time of FA was obtained at $30 \pm 5$ minutes and for BFS it is $40 \pm 5$ minutes. The final setting time of FA, BFS are 240, 300 minutes respectively. The slump of FA-BFS based concrete has higher values compared to conventional concrete. With increase in activator/binder 
ratio the slump values increased. For $500 \mathrm{~kg} / \mathrm{m}^{3}$ the slump of six mixes are between $80-200 \mathrm{~mm}$. Figures 1 and 2 shows casted and cured specimens. The compressive strength for the specimens of size $100 \mathrm{~mm} \times 100 \mathrm{~mm} \times 100$ $\mathrm{mm}$ are conducted and the strength obtained for 3, 7, 28 days are in figure 3 . The split tensile strength for the specimens of diameter $100 \mathrm{~mm}$ and height $300 \mathrm{~mm}$ are casted. The split tensile strength is measured for 3, 7 and 28 days results are in figure 4 . The prisms of size $500 \mathrm{~mm} \times 100 \mathrm{~mm} \times 100 \mathrm{~mm}$ are casted and cured. The specimens are tested for 7 and 28 days the results are indicated in figure 5.

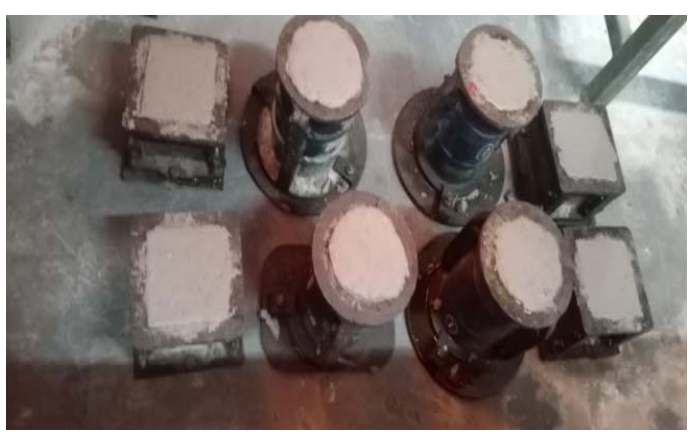

Fig 1: Casted specimens of AAC

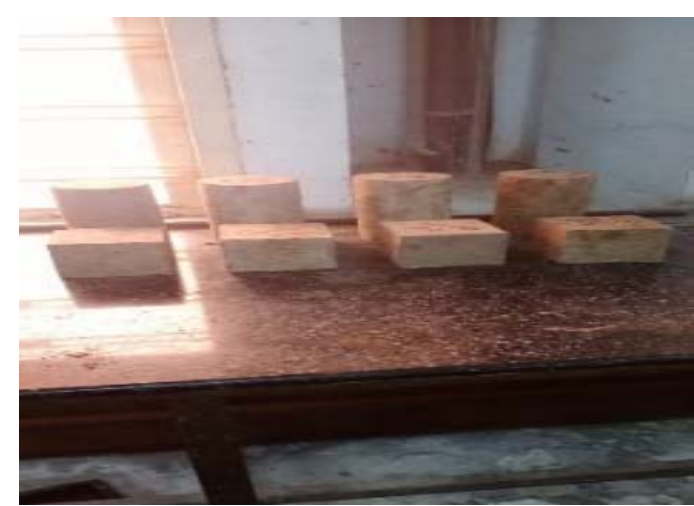

Fig 2: Ambient curing of AAC.

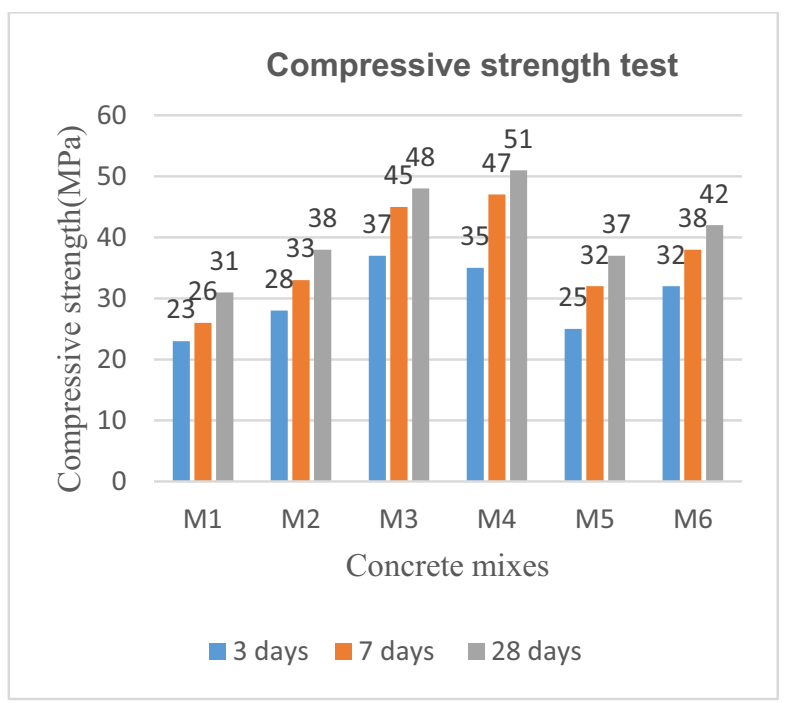

Fig 3: Results of compressive strength for 3, 7 and 28 days.

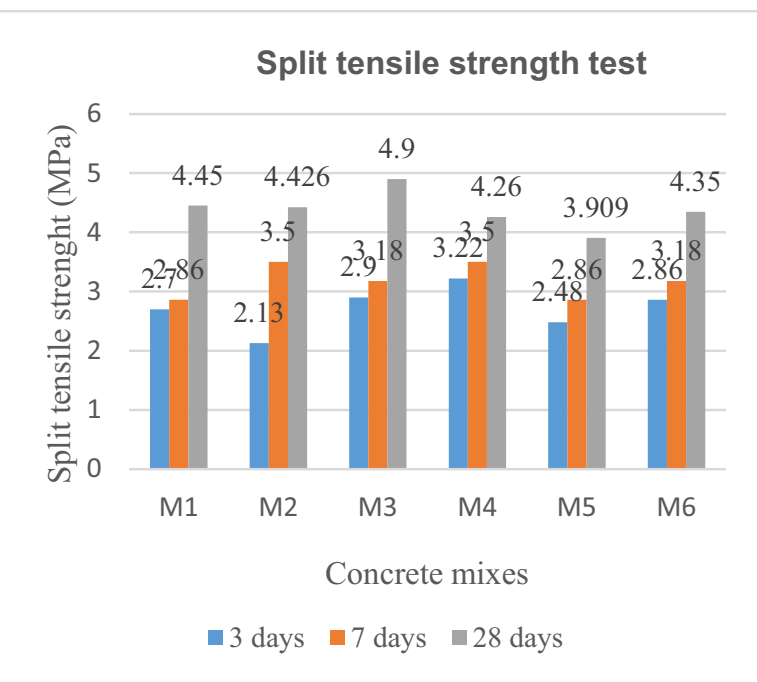

Fig 4: Results of split tensile strength for 3, 7 and 28 days 


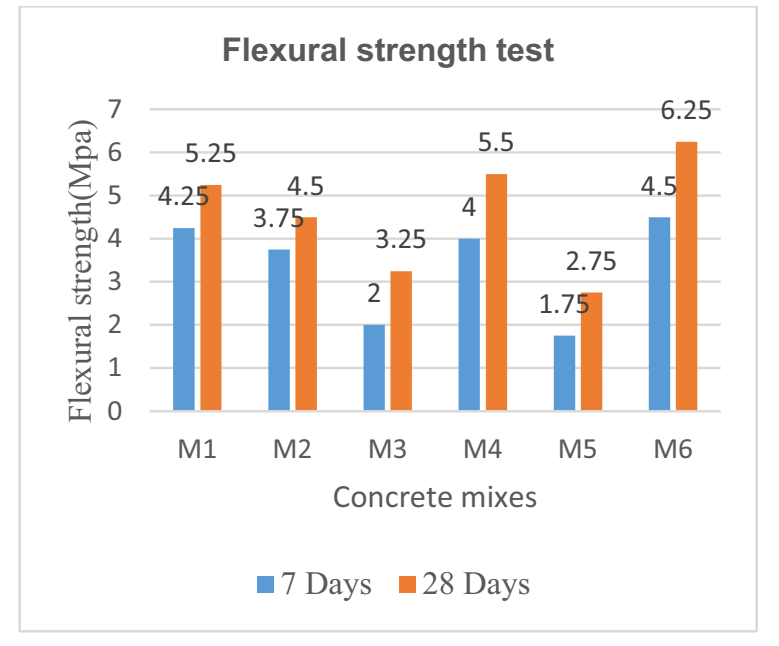

Fig 5: Results of Flexural strength for 7 and 28 days

\section{Conclusions}

1. The normal consistency of FA and BFS with High silica modulus activator showed satisfactory results. The workability of FABFS based AAC is higher compared to conventional concrete.

2. The outcomes of combined use of FA-BFS with sodium silicate activator reduced Rapid setting time of BFS and also gained strength without curing at elevated temperatures.

3. The compressive strength for Mix M4 with 0.65 activator/binder ratio and $50 \% \mathrm{FA}$ and BFS is higher. Activator/binder greater than 0.65 showed less compressive strength.

4. The split tensile strength is maximum at M3 mix where the flexural strength showed failure.

5. The flexural strength gained better performance at mix M6 where the compressive strength and split tensile strength showed decreased strengths.

\section{References}

1. Shah, Syed Farasat Ali, et al. "Improvement of early strength of Fly Ash-slag based one-part alkali activated mortar." Construction and Building Materials 246 (2020): 118533.

2. Satyanarayana, G. V. V., and C. Saikiran. "Effect on mechanical properties of M35 grade concrete by partial replacement of fine aggregate with copper slag." IJITEE, 12 (2019): 3759-3762.

3. Zhou, Xianyu, et al. "Mechanical properties of basalt and polypropylene fibre-reinforced alkaliactivated slag concrete." Construction and Building Materials 269 (2021): 121284.

4. Kishore, Kamal, and Nakul Gupta. "Mechanical characterization and assessment of composite geopolymer concrete." Materials Today: Proceedings 44 (2021): 58-62.

5. Fang, Guohao, and Mingzhong Zhang. "The evolution of interfacial transition zone in alkali- activated Fly Ash-slag concrete." Cement and Concrete Research 129 (2020): 105963.

6. Bhardwaj, Bavita, and Pardeep Kumar. "Comparative study of geopolymer and alkali activated slag concrete comprising waste foundry sand." Construction and Building Materials 209 (2019): 555-565.

7. Marjanović, Nataša, et al. "Physical-mechanical and microstructural properties of alkali-activated Fly Ash-Blast furnace slag blends." Ceramics International 41.1 (2015): 1421-1435.

8. Chi, Maochieh, and Ran Huang. "Binding mechanism and properties of alkali-activated Fly Ash/slag mortars." Construction and building materials 40 (2013): 291-298.

9. IS: 456, Indian standard plain and reinforced concrete code of practise Bureau of Indian Standards, New Delhi, 2002.

10. IS: 4031-1988 (PART 4): Determination of consistency of standard cement paste. Bureau of Indian Standards, New Delhi (1998)

11. IS: 4031-1988 (PART 5): Methods of physical test for hydraulic cement. Bureau of Indian Standards, New Delhi (1998)

12. IS: 1199-1959: Methods of sampling and analysis of concrete. Bureau of Indian Standards, New Delhi (1959)

13. IS: 516-1959: Indian standard code of practicemethods of tests for strength of concrete. Bureau of Indian Standards, New Delhi (1959)

14. IS: 383-1970: Specification for coarse and fine aggregate from natural source for concrete. Bureau of Indian Standards, New Delhi (1970).

15. Hojati, Maryam, and Aleksandra Radlińska. "Shrinkage and strength development of alkaliactivated Fly Ash-slag binary cements." Construction and Building Materials 150 (2017): 808-816.

16. Patankar, Subhash V., Yuwaraj M. Ghugal, and Sanjay S. Jamkar. "Mix design of Fly Ash based geopolymer concrete." Advances in structural engineering. Springer, New Delhi, 2015. 16191634.

17. Okoye, F. N., J. Durgaprasad, and N. B. Singh. "Effect of silica fume on the mechanical properties of Fly Ash based-geopolymer concrete." Ceramics International 42.2 (2016): 3000-3006.

18. Gugulothu, Vikas, and T. D. Gunneswara Rao. "Effect of Binder Content and Solution/Binder Ratio on Alkali-Activated Slag Concrete Activated with Neutral Grade Water Glass." Arabian Journal for Science and Engineering 45 (2020): 8187-8197.

19. Vikas, Gugulothu, and TD Gunneswara Rao. "Setting Time, Workability and Strength Properties of Alkali Activated Fly Ashand Slag Based Geopolymer Concrete Activated with High Silica Modulus Water Glass." Iranian Journal of Science and Technology, Transactions of Civil Engineering (2021): 1-10. 
20. G. Mallikarjuna, and TD Gunneswara Rao. "Final setting time and compressive strength of Fly Ashand GGBS-based geopolymer paste and mortar." Arabian Journal for Science and Engineering 40.11 (2015): 3067-3074. 